\title{
Burden of Non-Communicable Diseases (NCDs): Prevention is better Than Cure
}

\author{
Tahmina Afrose* \\ Department of Community Medicine, AIMST University, Malaysia
}

Submission: March 30, 2018; Published: May 07, 2018

"Corresponding author: Tahmina Afrose, Department of Community Medicine, Faculty of Medicine, AIMST University, Kedah, Malaysia,

Email: drafrosekeya@gmail.com

\begin{abstract}
Non-communicable diseases (NCDs) are the leading cause of mortality and morbidity worldwide. The harmful use of alcohol, unhealthy diet, physical inactivity and tobacco use are the leading modifiable risk factors for NCDs. Unhealthy diet and physical inactivity contributes to obesity. NCDs are now a major public health concern to individual quality of life and longevity. The World Health Organization has set some global strategies giving priorities on increasing surveillance system, improving public awareness and facilitating quality of care for chronic diseased cases to reduce the burden of NCDs. Political commitments to strengthening health systems, effective interventions, sufficient available resources and health equity are required to give more focus on preventive and control measures of non-communicable diseases.

Keywords: NCDs; Chronic disease; Obesity; Primary prevention; Secondary prevention; Health promotion; Health equity

Abbreviations: NCDs: Non-Communicable Diseases; WHO: World Health Origination; CVD: Cardiovascular Disease; COPD: Chronic Obstructive Respiratory Disease; HPV: Human Papilloma Virus
\end{abstract}

\section{Introduction}

Non-communicable diseases (NCDs) are one of the current threats. By 2030 NCDs are projected to account for more than $75 \%$ of premature deaths worldwide [1]. WHO defined non-communicable diseases (NCDs) as chronic diseases with prolonged duration and slow progression [2]. The most common non-communicable diseases (NCDs) are cardiovascular diseases, cancer, chronic respiratory diseases and diabetes. Noncommunicable diseases (NCDs) lead to $70 \%$ mortality in most of the developing countries and cardiovascular diseases are the leading cause. Smoking, alcohol intake, unhealthy dietary habits and the lack of physical activity are the major risk factors behind this. Early detection, Specific treatment as well as creating public awareness are the key steps to reduce the burden of the noncommunicable diseases (NCDs) [3].

\section{The Risk Factors}

The risk factors of non-communicable diseases has been classified into following two categories [4]: (Figure 1).

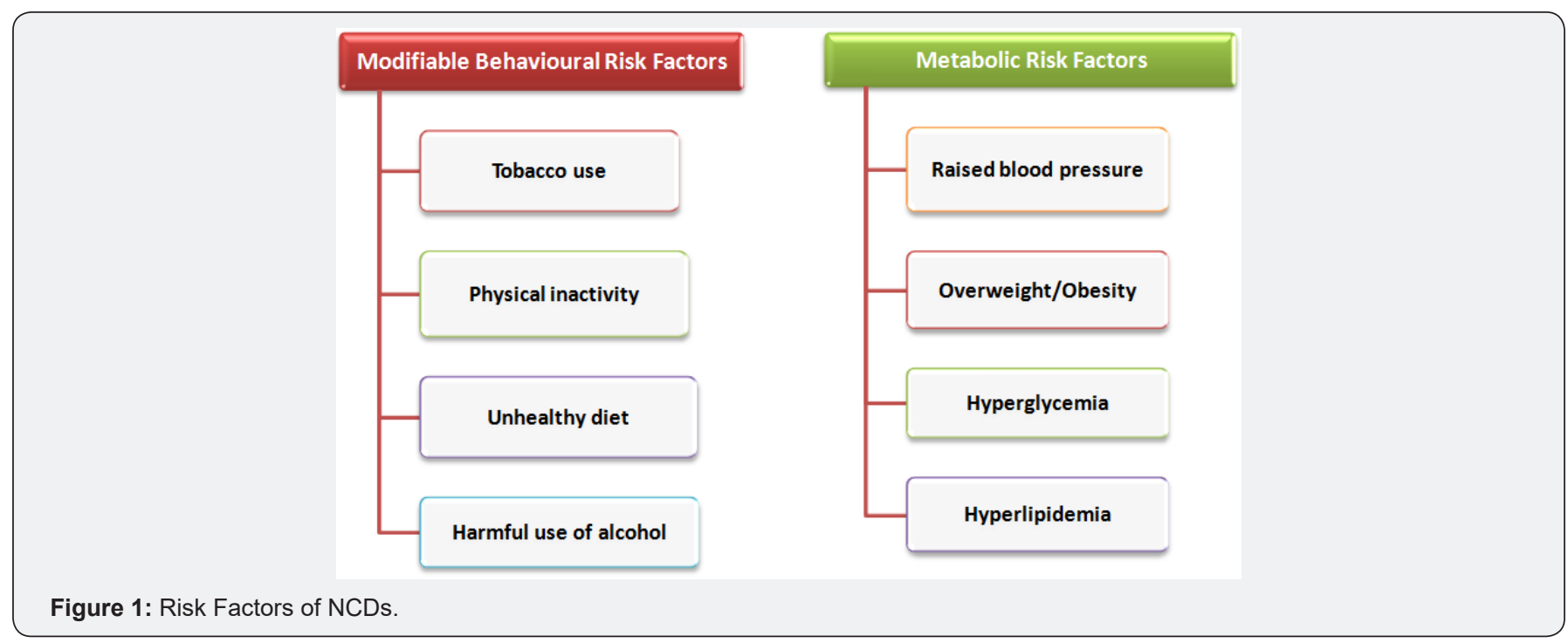




\section{Modifiable risk factors}

Modifiable risk factors those behaviors and exposure that can be changed and which are related to raise a person's risk of any of the NCDs. The major modifiable risk factors for NCDs include the followings [4]:

Tobacco use: Tobacco use is one of the major preventable causes of NCDs which accounts for 7.2 million mortality every year. Global trends for tobacco consumption are increasing day by day [5]. WHO projected that by 2020 it will cause around 7.5 million deaths annually [6]. By acting together it is a necessity to take immediate action against tobacco use [7].

Physical inactivity: Inadequate physical activity is another risk factor for developing major non-communicable diseases (NCDs) such as coronary heart disease, type 2 diabetes, and certain cancers [8]. Worldwide in every year about 1.6 million mortality are related to inadequate physical activity [4].

Unhealthy diet: Unhealthy diets are those diets which contain a high amount of fats, free sugars and salts. According to WHO about 4.1 million annual deaths have been reported due to excess salt intake [4]. Low intake of fruits and vegetables are associated with gastrointestinal cancer, coronary heart disease and stroke. Physical inactivity and unhealthy diets are the leading causes for overweight and obesity [9]. Excess consumption of saturated fat and trans-fat and high intake of sugar and salt with low intake of fruits and fresh vegetables contributes to dietrelated NCDs [10].

Harmful intake of alcohol: Uncontrolled alcohol consumption is associated with adverse health outcomes. Harmful intake of alcohol is related to develop more than $10 \%$ non-communicable diseases worldwide [11].

\section{Metabolic risk factors}

Metabolic risk factors are associated with harmful biochemical processes in human body that ultimately leads to adverse health outcomes. The common metabolic risk factors for non-communicable diseases (NCDs) includes: [4]

Raised blood pressure: Raised blood pressure is major risk factors for certain cardiovascular diseases such as coronary heart disease, ischemic heart disease and hemorrhagic shock and proper maintaining the blood pressure below $140 / 90 \mathrm{~mm}$ of $\mathrm{Hg}$ can reduce the risk for any cardiovascular complications [12].

Overweight and obesity: In both developing and developed countries the prevalence rate of overweight and obesity, which are considered as the key risk factors for non-communicable diseases (NCDs) are increasing day by day [13].

Hyperglycemia: Hyperglycemia or high blood glucose levels are one of the clinical features for patient suffering from diabetes mellitus [14]. Several studies showed that mortality rate and substantial neurological disability after acute stroke are commonly associated with diabetic patient than non-diabetic one [14-18].

\section{The Four Major Non-Communicable Diseases (NCDs)}

Unfortunately most of the communicable diseases are diagnosed in the advanced stages when the treatment is more costly and complications are more severe. By early diagnosis and prompt treatment these non-communicable diseases (NCDs) are preventable and controllable. According to WHO the major four non-communicable diseases (NCDs) are: [19,20]

\section{Cardiovascular disease (CVD)}

Cardiovascular disease (CVD) is the primary cause of death globally and in the last century heart disease and stroke became very common [20].

Cancer: By 2030 there are projected 11 million cases of cancers will be diagnosed annually in the lower-middleincome countries. Lung cancer is the number one killer which is associated with smoking. Other common cancers are colon cancer, uterine cancer etc [20].

Diabetes: Uncontrolled diabetes is associated with severe consequences like renal failure, stroke, heart disease and some neurological complications [21].

Chronic Respiratory Diseases: Chronic respiratory diseases include Chronic obstructive respiratory disease (COPD) and asthma. The leading cause of Chronic obstructive respiratory disease (COPD) is smoking. The other causes are air pollution, occupational dusts and chemicals. COPD is also preventable $[19,20]$.

\section{Disease Prevention}

According to WHO the disease prevention can be classified into following four levels: [22]

\section{Primordial prevention}

It includes the actions and measures that inhibit the emergence of risk factors in the form of environmental, economic, social, and behavioral conditions and cultural patterns of living. The main intervention in primordial prevention is through individual and mass education.

Primary prevention: These preventive measures are taken for avoiding the manifestation of a disease. The intervention under primary prevention includes health promotion such as oral \& dental hygiene education and specific protection. Example of specific protection includes immunization, nutritional and food supplementation etc.

Secondary prevention: Secondary prevention undertaken to halt the progress of disease at its earliest stage. Its intervention includes early diagnosis and prompt treatment of the diseased condition. The activities under secondary prevention include population-based screening programmers for early detection of 
diseases, provision of chemo-prophylactic agents to control risk factors of specific non-communicable disease etc.

Tertiary Prevention: The interventions under the tertiary prevention include disability limitation and rehabilitation. Disability limitation prevents the occurrence of further complications, impairments, disabilities and handicaps or even death. One example for disability limitation is application of plaster cast to a patient to prevent further disability like malunion or non-union. Rehabilitation can be medical, vocational, social, emotional or psychological rehabilitation (Figure 2).

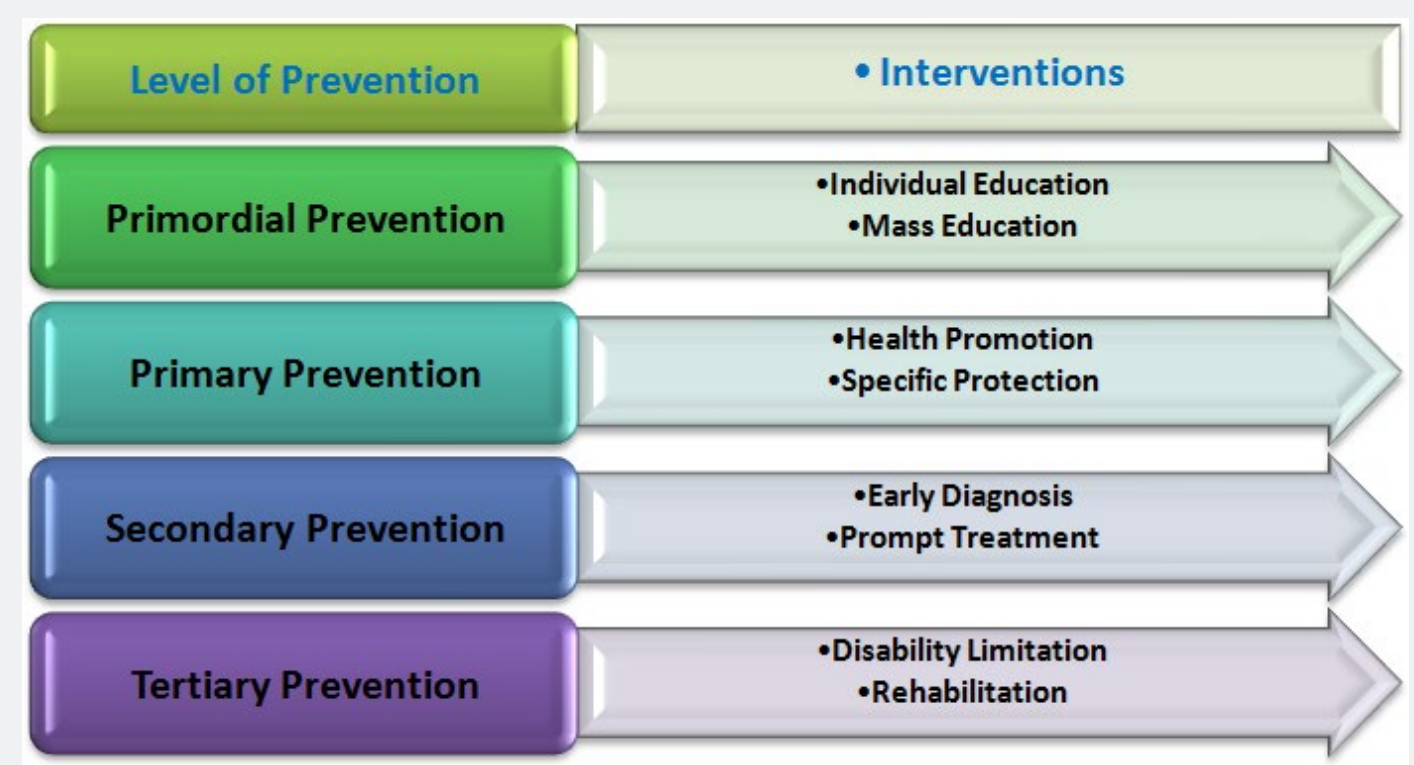

Figure 2: Level of Prevention.

Prevention of Non-Communicable Diseases (NCDs): The Way to Move Forward

In the Global Action Plan for the Prevention and Control of Non-Communicable diseases, 2013-2020 Guide, WHO has given some recommendations in the following areas: [23]

\section{Policy}

Public awareness and Political commitment: Raising public and political awareness about prevention and control of NCDs

Integrated action: Integration of NCDs into the poverty alleviation strategies.

Capacity-building: Strengthening international cooperation, capacity-building, health workforce, leadership, governance, multispectral action and partnerships for prevention and control of non-communicable diseases.

Effective communications: Effective communications has the key role behind raising public awareness.

Social mobilizations: Social mobilizations are a necessity for prevention and control of NCDs.

Budgetary allocations: It is a requirement to give more focus on budgetary allocations for prevention and control of NCDs.
Development of a national multisectoral policy: To develop and implement a national multisectoral policy with multi-stakeholder engagement for the prevention and control of non-communicable diseases is another key issue.

\section{Tobacco use}

\section{Taxation}

To reduce the easy accessibility and affordability of tobacco it is mandatory to increase taxation.

Smoke-free environments: It is required to make policy for creating and maintaining the smoke-free environments in all indoor workplaces, public places and also public transports.

Public awareness: Public awareness can be increased by effective implementation of different types of health promotion programs.

Banning: One of the effective policies is banning tobacco advertisement.

\section{Harmful use of Alcohol}

\section{Public awareness}

This can be achieved by encouraging communities for life time modifications.

Political commitment: Effective implementation of political commitment has a crucial role in the reduction of the harmful use of alcohol. 
At risk group: Providing early detection and immediate treatment at high risk groups can prevent any associated complications.

Policy: By strengthening and effective implementation the drink-driving policies and reducing easy accessibility and availability of alcohol can reduce the harmful effect of alcohol.

Restriction and Taxation: Restriction in alcohol advertising and increase tax on alcoholic beverages can prevent the easy accessibility of the alcohol.

\section{Unhealthy Diet \& Physical Inactivity}

\section{Healthy Food}

Giving more priorities on fruits and vegetables, less salt intake and replacing saturated fats with unsaturated fats are the preliminary step to prevent non-communicable diseases (NCDs).

Supportive Environment: Self and health-oriented environments for physical activity are one of the mandatory conditions for a healthy life.

Marketing of Healthy Foods: By decreasing the marketing of fast foods or junk foods is one of the fundamental steps to take prevention at the primordial level. It will help the children to practice a healthy food habits from their early developmental stages of life.

Strategy for Infant and Young Child Feeding: By effective implementation of the WHO global strategy for infant and young child feeding will ensure all children worldwide a healthy childhood.

Health Promotion Programs: By implementing different types of health promotion programs about healthy diet and physical activity in every community will increase the public awareness globally.

Food sanitation: By strengthening and proper maintaining food security and food sanitation and implementing food-related policy options will promote healthy diet.

\section{Financial Aspect}

By integrating very cost-effective non-communicable disease interventions into the basic primary health care package; sufficient trained workforce at Primary Health Care level; applying modern technologies in screening, diagnosis and for the treatment; availability of essential medicines for treatment of major non-communicable diseases (NCDs) in both public and private facilities; strengthening the health care system to identify the risk factors of the non-communicable diseases (NCDs) at all levels and implementation of cost-effective treatment modalities for palliative care will help to fight against non-communicable diseases (NCDs) burden worldwide.

\section{Specific Disease Related}

Cardiovascular Disease \& Diabetes: Prevention and control of Cardiovascular Disease and diabetes can be achieved by:
Appropriate drug therapies: By prescribing acetylsalicylic, atenolol and thrombolytic therapy (streptokinase) for acute myocardial infarction and for congestive cardiac failure with ACE inhibitor, beta-blocker and diuretics CVD and diabetes can be prevented and controlled in time.

Counseling: Counseling the individual at risk is the primary step for prevention and control of diabetes and cardiovascular diseases.

Population at risk approach: Application of total risk approach for the purposes of diagnosis, treatment and control of hypertension and diabetes.

Secondary prevention: Secondary prevention of rheumatic fever and rheumatic heart disease through early detection and prompt treatment.

Life time modification: Lifetime modification for type-2 diabetes is essential.

Immunization: Influenza vaccination for diabetic patient is necessary.

Pre-conception counseling: Patient with uncontrolled diabetes are associated with adverse birth outcomes. So the individual at risk of diabetes are required appropriate preconception counseling.

Secondary prevention: Secondary prevention of diabetes mellitus by appropriate drug therapy prescribing angiotensinconverting enzyme inhibitor to prevent progression of renal disease.

Tertiary prevention: Tertiary prevention of diabetes mellitus by detection of diabetic retinopathy followed by appropriate laser photocoagulation therapy to prevent blindness and appropriate interventions for foot care.

\section{Cancer}

\section{Primary prevention}

Primary prevention of liver cancer can be achieved by hepatitis B immunization.

Secondary prevention: Secondary prevention of cervical cancer can be achieved by screening either by cervical cytology or visual inspection with acetic acid.

Immunization: Vaccination against human papilloma virus (HPV) can reduce the risk of cervical cancer.

Population-based screening: Population based colorectal cancer screening is associated with timely treatment. Screening by mammography at high risk group can reduce the mortality rate of breast cancer.

\section{Chronic Respiratory Diseases}

\section{Cost-effective interventions}

Cost-effective interventions are a requirement to reduce indoor air pollution and to prevent occupational lung diseases. 
WHO guidelines: Appropriate use of the guidelines of WHO for treatment of asthma can reduce the further complications.

Immunizations: Influenza vaccination for patient with chronic obstructive pulmonary disease can reduce the mortality rates.

\section{Conclusion}

Some countries have already given priority to health equity to improve health for all. To reach the goal it should require proper implementation of effective strategic objectives, to be innovative, willing to learn from each other and to build the capacity by collaborative partnerships and networks. It is mandatory for every country to put NCDs in their social and economic development plans and here political supports are more crucial. Commitments to strengthening health systems are the essential key issue. For effective prevention and control of non-communicable disease most of the developing countries required technical expertise and resources from various disciplines. It is mandatory to limit the exposure of children to food and non-alcoholic beverage marketing. NCDs prevention and control can be achieved by multisectoral and multistakeholder initiatives and multilateral environment agreements that can lead to coordinated action.

\section{References}

1. World Health Organization (2008) The global burden of disease: 2004 update. World Health Organization, Geneva, Switzerland.

2. (2013) 10 facts on noncommunicable diseases

3. (2017) Noncommunicable diseases.

4. GBD 2015 Risk Factors Collaborators (2016) Global, regional, and national comparative risk assessment of 79 behavioral, environmental and occupational, and metabolic risks or clusters of risks, 1990-2015 a systematic analysis for the Global Burden of Disease Study 2015 Lancet 388(10053): 1659-1724.

5. Margaret Chan, World Health Organization, World Heart Federation, Tobacco: a major risk factor for Non-communicable Diseases, The NCD Alliance: Putting Non-communicable Diseases on the global agenda.

6. Mathers CD, Loncar D (2006) Projections of global mortality and burden of disease from 2002 to 2030. PLOS Med 3(11): e442.

7. World Health Organization (WHO) report on the global tobacco epidemic: the MPOWER package 2008.

This work is licensed under Creative Commons Attribution 4.0 License
8. Lee IM, Shiroma EJ, Lobelo F, Puska P, Blair SN, et al. (2013) Impact of physical inactivity on the world's major non-communicable diseases. Lancet 380 (9838): 219-229.

9. The world health report 2002 Reducing risks, promoting healthy life World Health Organization Geneva.

10. The challenge of obesity in the WHO European Region and strategies for response. Copenhagen: WHO Regional Office for Europe 2007.

11. Global Health Observatory (GHO) data.

12. Webber L, Kilpi F, Marsh T, Rtveladze K, Brown M, et al. (2012) High rates of obesity and non-communicable diseases predicted across latin america. PLOS One 7(8): e39589.

13. Umpierrez GE, Isaacs SD, Bazargan N, You X, Thaler LM, et al. (2002) hyperglycemia: an independent marker of in-hospital mortality in patients with undiagnosed diabetes. J Clin Endocrinol Metabo 87(3): 978-982.

14. Weir CJ, Murray GD, Dyker AG, Lees KR (1997) Is hyperglycemia an independent predictor of poor outcome after acute stroke? Results from a long term follow up study. BMJ 314(7090): 1303-1306.

15. Gray CS, Taylor R, French JM, Alberti KG, Venables GS, et al. (1987) The prognostic value of stress hyperglycemia and previously unrecognized diabetes in acute stroke. Diabet Med 4 (3): 237-240.

16. Candelise L, Landi G, Orazio EN, Boccardi E (1985) Prognostic significance of hyperglycemia in acute stroke. Arch Neurol 42(7): 661663.

17. Matchar DB, Divine GW, Heyman A, Feussner JR (1992) The influence of hyperglycemia on outcome of cerebral infarction. Ann Intern Med 117(6): 449-456

18. Woo J, Lam CW, Kay R, Wong AH, Teoh R, et al. (1990) The influence of hyperglycemia and diabetes mellitus on immediate and 3-month morbidity and mortality after acute stroke. Arch Neurol 47(11): 11741177.

19. World Health Organization (2011)Prioritizing a preventable epidemic: a primer for the media on non-communicable diseases.

20. Dans A, Ng N, Varghese C, Tai ES, Firestone R, et al. (2011) The rise of chronic non communicable diseases in southeast Asia: time for action. Lancet 377(9766): 680-689.

21. Diabetes Atlas International Diabetes Federation.

22. WHO Regional office report on "Health promotion and disease prevention through population-based interventions, including action to address social determinants and health inequity".

23. WHO Guideline Global Action Plan for the Prevention and Control of Non-Communicable diseases 2013-2020.

Your next submission with Juniper Publishers will reach you the below assets

- Quality Editorial service

- Swift Peer Review

- Reprints availability

- E-prints Service

- Manuscript Podcast for convenient understanding

- Global attainment for your research

- Manuscript accessibility in different formats

( Pdf, E-pub, Full Text, Audio)

- Unceasing customer service

Track the below URL for one-step submission https://juniperpublishers.com/online-submission.php 